\title{
The Innovation and Practice of Course Teaching Model of IP Routing and Switching Technique based on Certification of the Network Engineers
}

\author{
Yanli Feng,Dashe Li,Dapeng Cheng \\ College of Computer Science and Technology, Shandong Technology and Business University \\ Shandong Province, Yantai, China \\ lidashe@126.com,chengdapeng@sdtbu.edu.cn
}

\begin{abstract}
According to the requirements which are proposed by undergraduate engineering education authentication and the goals of training network engineering application-oriented talents with excellent career development ability and adaptability, which are based on the training program of network engineering professionals, the traditional teaching mode needs to be reformed urgently. This article proposes to integrate engineer qualification examination into classroom teaching, studying the methods and ideas of the process assessment model reform, in order to provide certain reference for reform and innovation of applied undergraduate course teaching mode.
\end{abstract}

Keywords-IP routing and switching, network engineers

\section{Introduction}

At present, for most students, the assessment mechanism is still the baton of their study. The evaluation of students'actual level is mostly based on the final "written test" exam, which really ignores the assessment of students' learning process.How to effectively use this baton to actively guide students is a problem we need to pay much attention in the curriculum reform.

IP routing and switching technology is a major course in network engineering.Practice teaching occupies a large proportion in its course teaching. Traditionally, the examination of this course are mainly carried out in the form of "written examination", focusing on the assessment of basic knowledge and skills to a great extent, and totally lacking comprehensive investigation of students'knowledge, ability and quality.Based on this, it is very necessary to build a diversified evaluation mechanism of IP Routing and Switching Technology under the guidance of the new teaching concept.This article will integrate the content of engineer certification into classroom teaching, making some useful explorations on the process assessment teaching mode, in order to accumulate some experience for the process assessment teaching mode of other courses.

\section{INDUSTRY CHARACTERISTICS OF NETWORK ENGINEER CERTIFICATION}

Network engineers are network technicians who master both the theoretical knowledge and operational skills of network technology through learning and training, being able to engage in the design, construction, operation and maintenance of computer information systems. They can also be responsible for the maintenance and communication of network hardware, software and other physical equipment.

At present, there are three network engineer certification in China, namely, HUAWEI, $\mathrm{H} 3 \mathrm{C}$ and CISCO. The certification training system of Huawei's network productis divided into three levels: Huawei Certified Network Engineer (HCNE), Huawei Certified Senior Network Engineer (HCSE) and Huawei Certified Network Expert (HCIE).The certification training system of Hua three's network product is divided into two levels; The certification training system of CISCO's network product is divided into three levels.

$\mathrm{H} 3 \mathrm{CNE}$ certification is mainly located in the planning, design, configuration and maintenance of small and mediumsized networks. The most important contents of authentication are grasping the basic principles of network communication TCP/IP protocol;grasping the principles and configuration methods of routers and Ethernet switches; grasping the principles, configuration and maintenance of WAN protocols; grasping the basic working principles and configuration methods of IP routing and routing protocols; being responsible for the installation, configuration and maintenance of low-end routers; handling common failures in network connection and software configuration of routers.

\section{REFORM IDEAS}

In order to improve the ability of students' engineering practice, in terms of teaching methods and contents, $\mathrm{H} 3 \mathrm{CNE}$ certificationis mainly oriented to the planning, design, 
configuration and maintenance of small and medium-sized networks in accordance with the assessment content of $\mathrm{H} 3 \mathrm{CNE}$ considered comprehensively, including students'practical ability, classroom performance and final examination results.

\section{A. Classroom teaching}

According to the process assessment of the course $<$ IP routing and switching technology $>$, based on the requirements of the syllabus, it is necessary to transform the ability of the course into the checking knowledge points of engineering certification, and to divide the knowledge points into competency modules, details as per Form1.In order to select the targeted certification level for different types of students later.For different practical projects, at the beginning of the examination, students should be informed of the ability engineers. When evaluating students, three aspects should be

requirements of different levels, different modules or projects.For example, for the switch initialization experiment project, the basic requirement is to simulate based on eNSP software using Console control line to configure and test the initialization.However, the practical requirement is how to use traditional twisted pair cable for further configuration modification and LAN test after Console cable configuration.Such different ability requirements can be adapted to students' needs of different abilities. Informing the ability standard of the project in advance, which can help both teachers and students to clearly evaluate what should be achieved and so on, so that the assessment will be more clear.

Table I Teaching mode

\begin{tabular}{|c|c|c|c|}
\hline Mode & Name & Mode & Name \\
\hline \multirow[t]{4}{*}{ Routing Mode } & Configure routing aggregation & \multirow[t]{3}{*}{$\begin{array}{l}\text { Switching } \\
\text { Mode }\end{array}$} & $\begin{array}{l}\text { Configure } \\
\text { aggregation }\end{array}$ \\
\hline & Routing Protocol & & VLAN \\
\hline & Configure static routing & & STP \\
\hline & $\begin{array}{l}\text { Configure dynamic routing ( RIP 、 } \\
\text { OSPF、IS-IS、BGP) }\end{array}$ & \multirow[t]{5}{*}{ Security Mode } & ACL \\
\hline \multirow[t]{4}{*}{ WAN Mode } & Configuration PPP & & NAT \\
\hline & Configuration CHAP & & IPSec \\
\hline & Configuration HDLC & & \multirow[t]{2}{*}{ Port security } \\
\hline & Frame relay & & \\
\hline \multirow[t]{3}{*}{ LAN Mode } & Ethernet technique & \multirow{3}{*}{$\begin{array}{l}\text { TCP/IP } \\
\text { The Principle }\end{array}$} & ARP、RARP \\
\hline & WLAN & & ICMP、DHCP \\
\hline & & & IPv6 \\
\hline
\end{tabular}

In the classroom teaching and experimental class, we certify the problems that appear in the assessment in order to enhance students'perceptual awareness.For example, when learning the switch module STP, build the network topology as shown in Figure 1. All switches are equipped with STP using Console line to configure parameters to determine which switch is selected as the root bridge.In the process of configuration, students have mastered how to configure the management ID of the switch and how to judge that switchis selected as the root bridge.

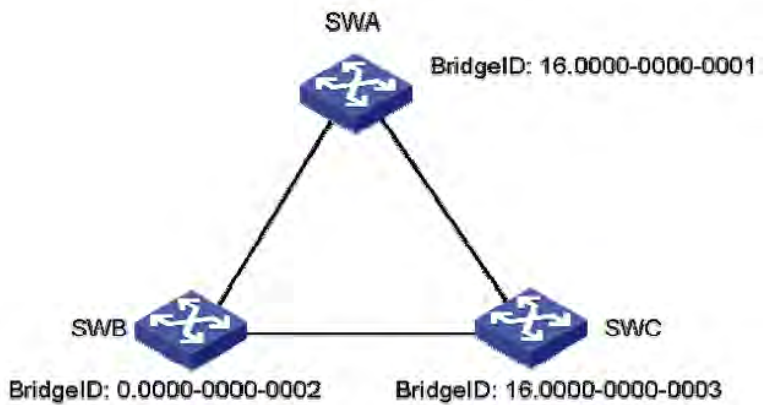

Figure 1 Experiment topology

\section{B. Actual operation}

This course uses the way of speaking while practicing. After the lecture, the students can immediately build a topology, $\log$ on to the real machine for operation, to verify the contents.In the process of operation, attention should be paid to the organic integration of each module, and the core content of each module can be practically exercised. While making an integrated networking, a company has four departments, Finance Department, Technology Department, Engineering Department and Outreach Department, with a total of 80 employees. The company has two servers (www, FTP) in the floor office building on average. The given intranet segment is 192.168.0/24, which requires a reasonable supply. Design requirements: (1) Providing topology map; (2) Selecting the equipment of two-layer switch, three-layer switch and router; (3) Extranet IP: 202.18.161.2/30, which requires intranet IP to access the IP address of the extranet; (4) Different departments are divided into different segments and different VLANs (10, $20,30,40)$, and different segments can communicate with each other; (5) Two servers are divided into (VLAN 50) and use the same network, meanwhile it can't conflict with the network segments among departments.In the course of teaching, NAT, VLAN and VLAN routing in engineering certification are 
integrated into classroom teaching, and students'understanding

\section{Evaluation mode}

Based on this, it is necessary to construct a new diversified evaluation mechanism for the course $<$ IP routing and switching technology $>$. When evaluating students, three aspects should be considered comprehensively: students'practical operation ability, normal performance and final examination results. The specific implementation plans are as following:

(1)Final examination

memory questions focuses on students' understanding of agreement and practical engineering problems. Among these, there will be some questions in English, accounting for 50\% of the total score, which are mainly aimed to practice the ability of students' English reading.

(2)Practical operation

Actual operationis the synthesis of basic operations which mainly examines the comprehensive operation ability of students. Students need to independently complete the work of network topology design, programming, testing and so of various protocols is exercised.

The final exam imitates the type of engineer certification, using multiple-choice questions, including single-choice questions and multiple-choice questions. It is basically the content of the engineer certification syllabus. The exam which contains 60 questions lasts for 60 minutes Those 60 questions are all multiple-choice questions and a small number of filling-in questions. The final exam which contains single-choice and multiple-choice but no pure

on.There are two periods of practical operation respectively in mid-term examination and final examination, accounting for $20 \%$ of the total score each time.

(3)Normal performance

Normal performanceis divided into two parts. The completion of the experiment mainly refers to the small test taken once a week, which is decided by the completion of the experiment, accounting for $5 \%$ of the total score. The other part is determined by the attendance rate and situation of answering the questions in class, accounting for $5 \%$ of the total score.

Table II Diversified assessment method indicator evaluation

\begin{tabular}{l|l|l|l|l|l}
\hline $\begin{array}{l}\text { Numb } \\
\text { er }\end{array}$ & Name & $\begin{array}{l}\text { Normal } \\
\text { performance } \\
(10 \%)\end{array}$ & $\begin{array}{l}\text { practical operation ability } \\
(40 \%)\end{array}$ & $\begin{array}{l}\text { Final } \\
\text { examination } \\
\text { result }(50 \%)\end{array}$ & $\begin{array}{l}\text { Total } \\
\text { points }\end{array}$ \\
\hline & $\begin{array}{l}\text { completion of } \\
\text { the experiment, } \\
\text { attendance rate }\end{array}$ & $\begin{array}{l}\text { two periods of practical } \\
\text { operation respectively in } \\
\text { mid-term examination and } \\
\text { final examination }\end{array}$ & $\begin{array}{l}\text { Final } \\
\text { examination }\end{array}$ & \\
\hline
\end{tabular}

V.Conclusion

\section{IMPLEMENTATION EFFECT}

The reform of this teaching mode promotes students' certificate obtaining and competition.Through the implementation of Double-certificate teaching materials, case study teaching, virtual-real combination of network experimental environment and computer simulation certification and other methods in the classroom, using the quality development project as a carrier after class, training the students for certificate obtaining and competition, the students have achieved some great results.Students have won many awards in the iCAN international innovation and entrepreneurship competition and the Chinese university student computer contest. Those awards include the third prize of the 2018iCAN International Innovation and Entrepreneurship Competition, the second prize and the third prize of the East China Competition for Chinese University Students Computer Competition.Take the students of 15 network engineering as an example, 40 of the 52 students in the class have enrolled in the network qualification examination.Students' enthusiasm for learning has been unprecedentedly high.
This article constructs a teaching mode reform scheme of $<$ IP Routing and Switching Technology $>$ based on Network Engineer certification, and has done some implementation.Practice has proved that this teaching mode can effectively solve the differences between the training objectives of network engineering specialty in local undergraduate colleges and universities and social needs, and the overall optimization of the curriculum system and teaching content of network engineering specialty.

\section{Acknowledgment}

This work is partially supported by National Natural Science Foundation (No.61070175), Shandong technology and Business University Teaching Innovation Project(11688G201803). The authors gratefully acknowledge the suggestions of the reviewers which have helped improve the presentation.

\section{References}

[1]Zhang Min,Li Jiye,Yang Mingguang etal.Exploration and Implementation for Class of Routing and Switching. Computer Education, 2018.10:14-17 
[2] Sun Liangxu,Wu Jiansheng. Research on Construction of Teaching environment of Routing and Technology course based on engineering practive Driving. Experimental Technology and Management,2014,31(9):212215

[3]Liu Jing. .Exploration and Implementation for Course of Routing and Switching based on CDIO. Computer Education, 2017.7:52-55

[4]Gao Guangyong,Yao Shimao.Discussion on Examination of Routing and Switching Configuration.Education Teaching Forum,2016.12:109-111
[5] Razvan Bologa, Ana Ramona Lupu(2014). Organizational learning networks that can increase the productivity of IT consulting companies. A case study for ERP consultants. Expert Systems With Applications, 1:126-136 [6] Gemma Tejedor,Jordi Segalàs,Martí Rosas-Casals(2018) Transdisciplinarity in higher education for sustainability: How discourses are approached in engineering education. Journal of Cleaner Production, 1:29-37 